\title{
Space-time clusters of crime in Stockholm, Sweden
}

\author{
"Adriaan Cornelis Uittenbogaard (a), Vania Ceccato (b)," a*
}

"Dep. of Urban Planning and Environment, Royal Institute of Technology, Drottning Kristinas väg 30, 10044 Stockholm, Sweden"

\begin{abstract}
The aim of the study is to detect geographical clustering of offences over time using Kulldorff's scan test (SaTScan version 9.01; Kulldorff 2010) and police recorded data over Stockholm city, the capital of Sweden. This technique has a rigorous inference theory for identifying statistically significant clusters. The space-time scan statistics are used in a single retrospective analysis using data from 1st January 2006 to 31st December 2009. Four years dataset is collapsed into 'one year'. All space and time dimensions of the data are kept (by day and location) except 'year'. Clusters over the hours of the day, weekday and weekend and by seasons were tested. Total population but also day time and night time populations were used as reference. Findings show clear distinct patterns of concentration for violence (assault and threat) and property crimes (theft, robbery and burglary) over time and space. Whilst property crimes tend to happen more often in the afternoons in the centre and regional commercial centers in the southern and western parts of Stockholm, violence takes place more often in the night, and is heavily concentrated in large parts of the city centre. Weekends are more targeted than weekdays for both offences. Regardless day of the week, the main urban core contains the most likely cluster that extends also to commercial and socially disorganized areas in the west and south Stockholm. Whilst property crime does not show significant differences over the seasons, violence does (winter and summer). The most likely clusters tend to be fairly constant in space over time.
\end{abstract}

(C) 2010 Published by Elsevier Ltd. Selection and/or peer-review under responsibility of Spatial Statistics 2011

"Keywords: spatial concentration; Kulldorff's scan test; Poisson discrete; temporal variation"

* Corresponding author. Tel.: +46-8-7909221.

E-mail address: acui@kth.se 


\section{Introduction}

Quetelet [1] suggested that the greatest number of crimes against a person is committed during summer and the fewest during winter. Since his seminal work, researchers have found empirical evidence on how crime levels vary over time and space (for a review see Cohn [2], Cohn and Rotton [3], Ceccato [4]). Some relate these temporal differences to the influence of weather on behavior (Anderson et al. [5]) whilst others associate them to variations in people's routine activity (Cohen and Felson [6]). Routine activity theory suggests that an individual's activities and daily habits are rhythmic and consist of patterns that are constantly repeated. Most crimes depend on the interrelation of space and time: offenders' motivation, suitable targets (victims) and absence of responsible guardians. This is the basis of the explanation of the mechanisms behind seasonal (summer-winter) and weekly (weekend-weekday) variations of crime over time and space.

In order to detect these variations of crime over space and time cluster techniques are used. The advance of new technologies for data storage and analysis such as Geographical Information System (GIS) has led to systems for visualising and analysing the growing amounts of geocoded data, including crime. "These techniques are making geographical analysis of crime data more in-depth and interactive than they were in the past and therefore space can now be addressed more dynamically, both in time and space. Spatial analysis of crime data often uses information on the unique location of individual crimes ( $\mathrm{x}, \mathrm{y}$ co-ordinates) or aggregated data (combining individual point data into larger areal units, such as a city's statistical units)" (Ceccato [7]).

In this article, we test the use of Kulldorff's scan test to detect hotspots of violent and property crimes in Stockholm, Sweden.

\section{Objectives}

The objective of this study is to detect geographical clustering of offences over time using a Poisson discrete model and police recorded data over Stockholm city, Sweden. This will be achieved by assessing the concentration for violent and property offences in three moments in time: hours of the day, weekend and weekend and seasonally. For cluster detection during the day, two different reference populations are tested: day time and night time population and results are compared.

The structure of the article is the following. First, we review some relevant literature on space-time clusters and set the hypotheses of study in section 3. In section 4 we present our area of study and the data used. Section 5 covers the methods applied and results retrieved. In section 6 the results are discussed and final conclusions are drawn.

\section{Space-time clusters: theory and hypotheses}

Until recently, the role of space (and space-time) was not explicitly acknowledged in the methodology used in crime geography studies, but it is central in a number of respects" (Anselin [8]). An important reason is that knowing where and when crime happens is fundamental for police intervention (Ratcliffe [9]). Both Ratcliffe [9] and Anselin [8] emphasize the importance of spatial techniques to detect and analyse space-time in crime data. Nakaya and Yano [10] emphasize the need to visualize both crime patterns in space and time to get a grip on the movement of clusters over time and space instead of focusing on individual clusters. The study on crime clusters in Kyoto showed that the use of both kernel density based analyses and space-time scan statistics analyses are very well complementary to each other.

Johnson et al. [11] used Monte-Carlo simulations and Knox's ratio results to identify space-time clusters of burglary. Their cross-national findings showed that burglaries tend to be clustered in space but 
more important in time as well; clusters decayed as time elapsed. Johnson and Bowers [12] use Knox's ratios but in combination with the Mantel technique to identify burglary clusters in space and time. The result of a two step analysis, for first spatial clustering of 'close pairs' and secondly space-time clustering, is that clusters of burglary appear more stable in time and movement in space occurs only into the vicinity in different time periods.

Kulldorff's scan test has successful been applied in the literature for both cities in the North and South hemisphere. LeBeau's study [13] used the Kulldorff's scan test for a risk based assessment using spacetime cluster of crime at the Charlotte-Mecklenburg, North Carolina Police Department. Ceccato [4] focused on space-time clustering (Poisson discrete model) of homicides in Sao Paulo (Brasil) and showed a very seasonal pattern which changes spatially according to warmer and colder months of the year.

Taken together, the existing literature on Kulldorff's scan test is encouraging with regards to spacetime cluster detection of hotspots of crime. For the purpose of this study, we follow the recent strand of research and hypothesise that the Poisson discrete model in Kulldorff's scan test will provide robust results for the case of Stockholm. The analysis makes use of four years crime data over Stockholm city to test the following hypotheses:

1) Both violent and property crimes show daily, weekly and seasonal variations over time and space.

2) Crime opportunities tend to be concentrated where people converge (city centre, commercial areas, and central stations) but also in areas with signs of social disorganization.

3) Hotspots of crime are sensitive for the population basis used in the test. Night time population tends to shrink hotspots where people live (periphery of the city) whilst day time population affect the size of hotspots in the opposite direction

\section{4. . The study area and data}

The study area is Stockholm city only. The data used is within the borders of the municipality, which covers an area of $216 \mathrm{~km} 2$ and a total population of 790.642 (2007). The city is divided in 408 small units of analysis (basområde), with an average population of 1.937,85 and standard deviation of $1.833,11$. Crime data is extracted from official records of the Stockholm Police over four years: 2006 to 2009. Of all the selected records 6.3 per cent was eliminate as those either lacked coordinates, dates, were outside the study area or were registered before the recorded year. The records included all recorded crimes of which we selected five categories useful for this study: violence, threat, theft, burglary and robbery. These selected records comprehend 349.492 cases. These four years were collapsed into one year in order to create a more robust dataset. The records contained information on the offence, place ( $\mathrm{x}, \mathrm{y}$ coordinates) and time (by minute). Besides the crime records, demographic data of Stockholm Municipality was used to run the cluster detection for seasonal variations. We had total population for each small unit of analysis as well as night time and day time population. Night time population shows a high correlation with total population whilst day time population reflects people's movement patterns in the city. Table 1 indicates that more offences seem to happen during weekend than weekdays. This makes a case for us to check if there also is any variation in crime levels in space. This will be examined further in the paper.

Table 1. Average statistics of two types of crime in Stockholm, 2006-2009

\begin{tabular}{|c|c|c|c|c|c|c|c|}
\hline & \multirow{2}{*}{$\begin{array}{l}\text { Total } \\
4 \text { years }\end{array}$} & \multirow{2}{*}{$\begin{array}{l}\text { Average a } \\
\text { year }\end{array}$} & \multirow{2}{*}{$\begin{array}{l}\text { Average } \\
\text { an hour }\end{array}$} & \multicolumn{2}{|c|}{ Average weekdays } & \multicolumn{2}{|c|}{ Average weekends } \\
\hline & & & & One day & One hour & One day & One hour \\
\hline Violent & 75117 & 18779.25 & 1.84 & 43.51 & 1.81 & 61.99 & 2.58 \\
\hline Property & 274375 & 68593.75 & 6.98 & 180.95 & 7.54 & 196.96 & 8.21 \\
\hline
\end{tabular}




\section{Indentifying space-time clusters of violent and property crime in Stockholm}

This study explorers when and where crime happens in Stockholm and therefore investigates three different moments in time. The analysis is divided in three parts; crime during the day, between weekdays and weekends and whether there are any seasonal variations. For all three moments the clustering of crime has been assessed using the Kulldorff's space-time cluster test based on a discrete Poisson model. This model uses a Poisson distribution of the number of cases at each location, under the null hypothesis that the expected number of cases in each area is proportional to the population in that area [14]. The space-time scan statistic is defined by a cylindrical window with a circular geographic base and with height corresponding to time. This cylindrical window is moved in space and time, so that, for each possible geographical location and size, it also visits each possible time period. An infinite number of overlapping cylinders of different size and shape are obtained, jointly covering the entire study region, where each cylinder reflects a possible cluster. This procedure is used to ensure data robustness (there is a higher power to pick clusters up with the collapsed data than one year dataset) [14]. The Kulldorff's scan test uses space-time statistics from the user's input. The input data was created separately for each different run. In order to have an effective but comprehensive data input, all crime records were linked to their respective small unit areas (basområd) as defined in the Stockholm population data using GIS (population basis) This implies that that the scans are not run based on the exact coordinates of each separate crime record but on the attributes (population) of each pair of coordinates of the small unit areas. For cluster detection during the day, two different reference populations are tested: day time and night time population and results compared. Originally, Stockholm Municipality consists of 408 small unit areas, but a couple of these units have low population counts (less than 50 inhabitants). To improve the population basis for running the scan tests, about 40 units were aggregated to the neighboring polygons using GIS; so that none showed a population count lower than 50. The space-time scans can be executed within different time frames defined by the user. For the scans run during this study, the maximum temporal cluster size window was set to seven days (if applicable) so that the crime clusters were identified at a maximum length of a week. For spatial scan limits two ranges have been used: one being maximum 50 per cent of the population at risk and the other a maximum of 10 per cent of the population.

\subsection{Clusters during the day}

During the day people are on the move and execute different patterns related to their destinations and handlings. This also relates to the opportunities for different kinds of offences. The two types of crime show two different patterns over the day; property crimes happen more during day times and violent crimes are more committed during night times. There is a peak for property crimes at $5 \mathrm{pm}$ and at $2 \mathrm{am}$ for violent crimes (Figure 1).

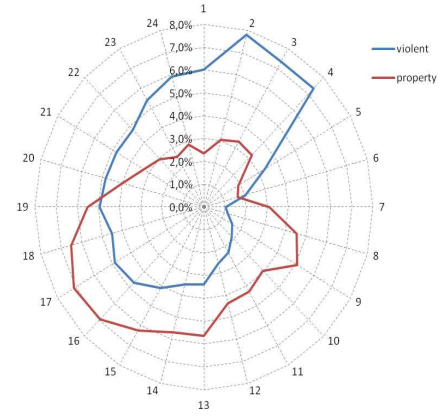

Figure 1. Percentage of violence and property crimes by hour of the day in Stockholm, 2006-2009. 
To run a cluster analysis on the peak and low hours for each crime, the collapsed police data was split in selections for each hour. As the time frame was already decided, being the input data of one hour, a spatial only scan using Kulldorff's SaTScan was run for violent crimes at 2am to 3am, property crimes from $5 \mathrm{pm}$ to $6 \mathrm{pm}$, violent crimes $6 \mathrm{am}$ to $7 \mathrm{am}$ and property crimes $6 \mathrm{am}$ to $7 \mathrm{am}$. The population data was retrieved from the socio-economic data set and is based on the night time population for the selected night hours ( $2 \mathrm{am}$ and $6 \mathrm{am}$ ) and on day population for the $5 \mathrm{pm}$ property crimes. There have also been additional test using total population in order to check for differences, which highly correlated with night population.

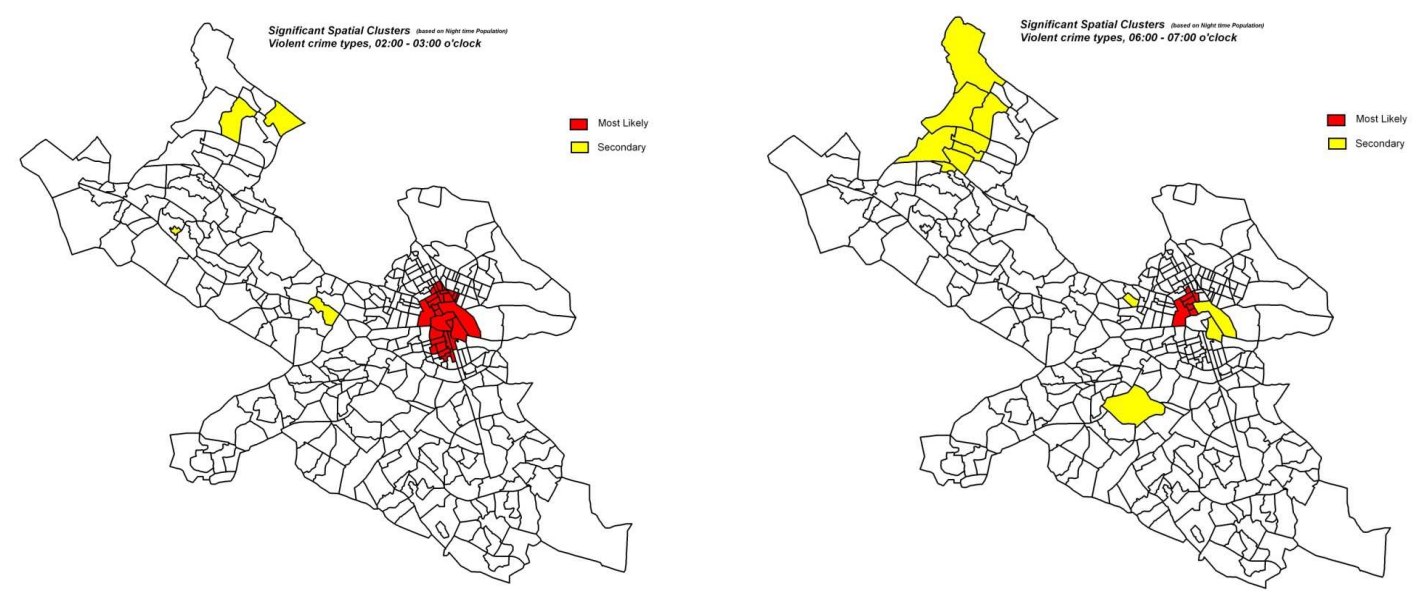

Figure 2. Clusters of violent crimes at a) 2am (Peak frequency) and b) 6am (Lowest frequency)

The spatial clusters appearing as hotspots during the night show a more concentrated violent pattern (Figure 2) that shrinks when moving towards the lowest peak, 6am. Property crimes (Figure 3) increase in terms of clusters at the highest peak, $5 \mathrm{pm}$, and sneaks into more suburban areas where the population is lower during day time as people are at not at home but gone to work or leisure activities.
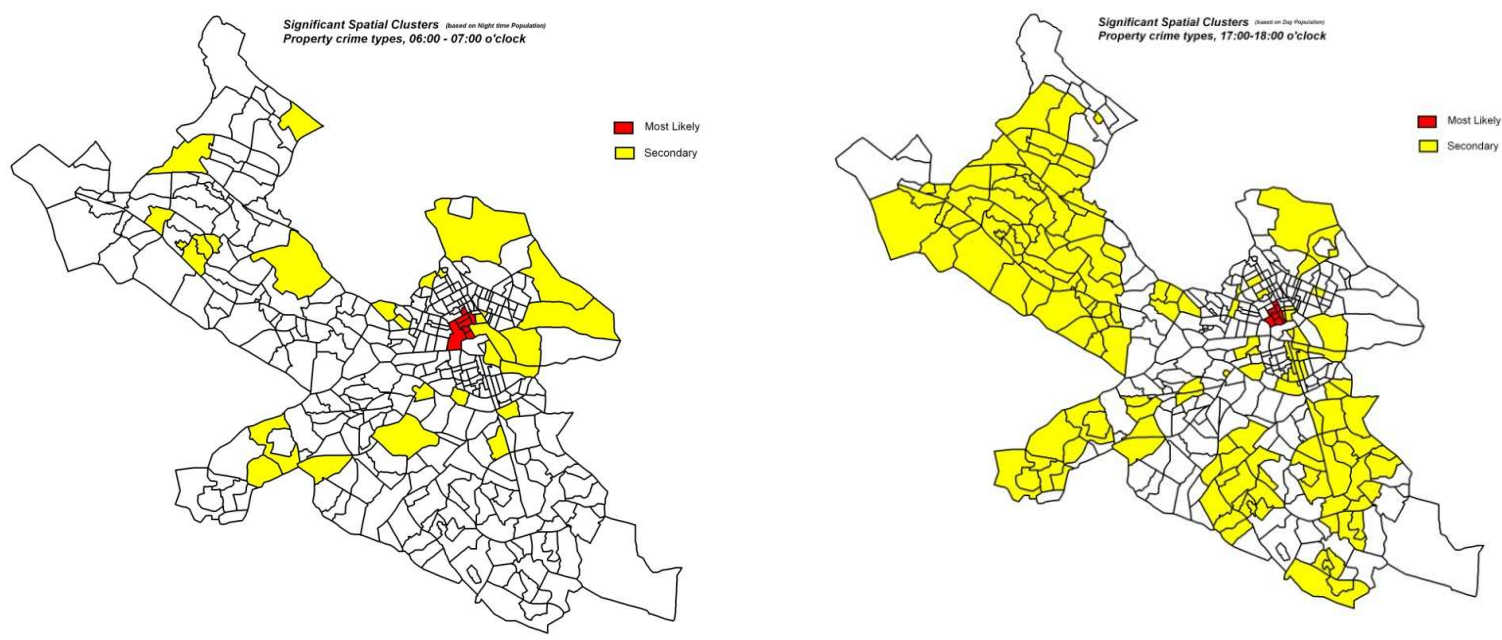

Figure 3. Clusters of property crimes at a) 6am (Lowest frequency) and b) 5pm (Peak frequency) 


\subsection{Clusters in the week}

The literature shows evidence of significant difference in crime incidence between weekends and weekdays. Peak periods for assaults and robberies were in the early hours of the morning on weekends, that is, between 0001 and 0300 on Saturdays and Sundays. Assault and robbery rates during these times were more than twice the average rates in Sydney Australia (Rocheldson [15]).

Our results show that weekends tend to be more prone to crime activities as a consequence of the unstructured activities undertaken during the weekend. By selecting two data sets, for both weekdays (Monday - Thursday) and weekends (Friday - Sunday), as input for the Kulldorff's scan test, clustering was detected for both periods.

For both crime types A-nova tests show a significant difference between weekdays and weekends. Property crimes show significance at a 90 per cent level whereas violent crime is significant at a 99 per cent level (Scheffe test). Violent crime clusters shrink during the weekend and show a more concentrated pattern for specific locations in the suburbs. The city center shifts in direction for weekends, including the area in the east where more bars and clubs are located contrary to the weekday's cluster which is more concentrated around the central station.

\subsection{Seasonal clusters}

Research has been inconclusive on whether crime varies seasonally (Cheatworrd [16], Landau and Fridman [17] and Ceccato [4]) but evidence tends to show that crime varies over time. In the Northern Hemisphere, Cheatword [16] shows that there was no season for homicide but "the months of December, July, and August are significantly more likely to be among the months in which homicide is high for any given year". Landau and Fridman [17] found that while homicide does not vary significantly over the year, robbery does and would peak during the winter (November through March) Assault and robbery incidents were more prevalent in the summer months in Sydney, Australia (Jochelson [15]) whilst Hipp et al. [18] shows that both violent and property crimes vary seasonally. They show, for instance, that hat property crime rates are primarily driven by pleasant weather. Homicides show seasonal variations also in Sao Paulo, one of the largest cities of the Global South. Do violent and property crimes vary in Stockholm? A-Nova test showed that levels of violent crimes differ between winter and summer; there is a significant difference of over five crimes a day (Table 2). Property crime does not vary significantly between seasons.

Table 2. Differences in violent crimes by season

\begin{tabular}{llll}
\hline & Crime Levels Mean & F-test & Scheffe \\
\hline Winter (1) & 48.19 & $2,901 *$ & $1.3 / 3.1$ \\
\hline Spring (2) & 51.90 & & \\
\hline Summer (3) & 53.54 & & \\
\hline Autumn (4) & 51.98 & &
\end{tabular}

To detect variations of crime over seasons, the full four year dataset was broken down into four parts (Winter from December till February Spring was from March to May, Summer ranged from June to August and Autumn includes September to November Scans for both violence and property crimes were run using the total population with a 7 days as maximum length in time of a cluster (a week). The first test used the default spatial limit of the population a 50 per cent but the results were unsatisfactory. Violent crimes showed at first a surprising pattern where one secondary cluster covered half of the study area at 
only one point in time: the first of January, in the winter. A common practice is to decrease the spatial limit to 10 per cent of population at risk. Figure 4 shows the difference between summer and winter after adjusting for the spatial limit to 10 per cent of population at risk.

The city centre is a stable hotspot for both crime types during different seasons, there is a mixed use of activities and people converge at the central station on their way to and from places. Stockholm's city centre is rather compact and concentrates shops, offices and bars. There is however a variation in time as violent crimes in the city centre concentrate during the winter months whereas, property crimes the city centre shows up during summer months.

Following the A-nova test, the space-time scan clusters show slightly different clusters for violence during the winter and summer. Moreover, the city centre has clearly shrunk while moving into summer months when the violent crime clusters seem to be positioned more in the outer-suburbs of Stockholm (Figure 4). Areas in the periphery of Stockholm municipality mainly concentrate housing areas with (regional) shopping centra located at transportation hubs which present steady clusters over time and space.

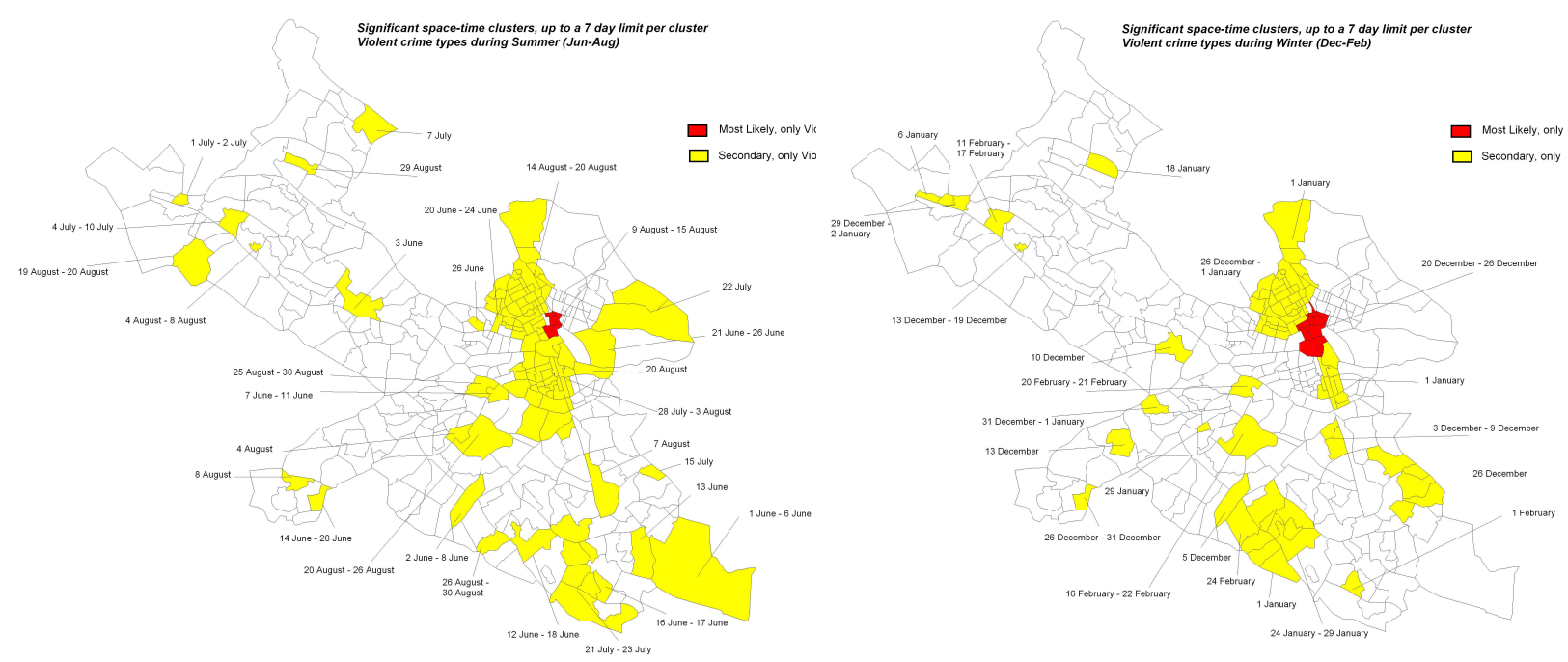

Figure 4. Violent crime clusters during a) Summer and b) Winter.

\section{Discussion of results}

The Kulldorff's scan test is an useful tool to identify hotspots for space-time clustering in Stockholm either by hour (slices in space), weekly or seasonally.

Our findings confirm the first hypothesis that the crime types vary over time and space. The change of levels of crime by hour provides a clear distinction between violent and property crimes. In Stockholm clusters tend to happen around some common areas, regardless time. Nevertheless, a more spread out pattern can be observed for summers as compared to winters. The second hypothesis prompts that crime opportunities are related to the place where people meet, as our clusters over time and season prove to be correct for the city centre and suburban centers. The findings also show evidence that corroborates social disorganization theory (Most of the persistent clusters are found in areas with strong social disorganization risk facors, low social control, located in for instance Vällingby (northwest), Farsta (south) and Rinkeby (north)). Thirdly, the hypothesis points out the effect of the population base used for 
the scan test. However, the Kulldorff's space-time scans provide the undeniable result of a constant hotspot for violent and property crimes in the city centre regardless time or date or population base. Besides that, for secondary clusters the night time population affects the size of hotspots to shrink there where people live (in the periphery of the city) while on the other hand day time population increases the size of clusters in the periphery as people head for work elsewhere (for instance city centre) and the population base is then lower.

For further research we would suggest to run a second type of analysis looking at the relations between the clusters. Also could one run the models with different parameters as in maximum length of days and population at risk for clusters and take a closer look on the space-time clusters with respect to date and place. As the most dominating cluster, the exclusion of the city centre may also provide more exhausting results for the rest of the Stockholm municipality, where then can one find the hotspots? Are they similar or did they change? And for even more interesting results for Stockholm one could have a look at cold spots too, in comparison with the hotspots. How do these change over time, do they act in the same way?

\section{Acknowledgements}

The research support of the Traffikverket and Stockholm municipality is gratefully acknowledged. Thanks also to Ulla Wittrock (of the Police in Stockholm County), Stefan Liljevall (Stockholm Statistics) for providing data for the analysis.

\section{References}

[1] Quetelet AJ. A treatise on man and the development of his faculties. A facsim. reproduction of the English translation of 1842. Gainesville, Florida: Scholar's Facsimiles and Reprints; [1842] 1969.

[2] Cohn EG. Weather and crime. In: British Journal of Criminology 1990; 30: 51-64

[3] Cohn EG, Rotton, J. Even criminals take a holyday: instrumental and expressive crimes on major and minor holidays. In: Journal of Criminal Justice 2003; 31: 351-360

[4] Ceccato V. Homicide in Sao Paulo, Brazil: Assessing spatial-temporal and weather variations. In: Journal of Environmental Psychology, Elsevier; 2005; $25: 307-321$

[5] Anderson CA, Anderson KB, Dorr N, DeNeve KM, Flanagan M. Temperature and aggression. In Zanna MP, editor, Advances in experimental social psychology, New York: Academic Press; 2000, p. 33-133

[6] Cohen, LE, Felson M. Social Change and Crime Rate Trends: A Routine Activity Approach. In: American Sociological Review. 1979; 44: 588-605 [7] Ceccato, V. (2008) Crime and space: patterns of offences and offenders' paths to crime portrayed by Geographic Information Systems (GIS), In: Lunden T, editor Kartan och Verkligheten, The Swedish Society for Anthropology and Geography YMER,; 2008, p. 191-208

[8] Anselin L, Cohen J, Cook D, Gorr W, Tita G. Spatial Analyses of Crime. In: Measurement and Analysis of Crime and Justice, Criminal Justice, U.S Department of Justice, Office of Justice Programs. Washington, U.S.; 2000; 4: 213-262

[9] Ratcliffe J. Crime Mapping: Spatial and Temperol Challenges. In: Piquero AR, Weisburd D, editors, Handbook of Quantitative Criminology, Springer Science; 2010, p.5-24

[10] Nakayo T, Yano K. Visualising Crime Clusters in a Space-time Cube: An Exploratory Data-analysis Approach Using Space-time Kernel Density Estimation and Scan Statistics. In: Transactions in GIS, Blackwell Publishing; 2010; 14(3): 223-239

[11] Johnson SD, Bernasco W, Bowers KJ, Elffers H, Ratcliffe J, Rengert G, Townsley M. Space-Time Patterns of Risk: A Cross National Assessment of Residential Burglary Victimization. In: Journal of Quantitative Criminology 2007; 23(3): 201-219

[12] Johnson SD, Bowers KJ. The Stability of Space-Time Cluster of Burglary. In: British Journal of Criminology, Oxford Journals; 2004 ; 44 (1): 5565.

[13] LeBeau JL. Demonstrating The Analytical Utility of GIS for Police Operations A Final report. Southern Illinois UniversityUnited States; 2000

[14] Kulldorff M. SaTScan User Guide for version 9.0. 2010.

[15] Jochelson R. (1997). Crime and Place: An Analysis of Assaults and Robberies in Inner Sydney, General Report Series. Sydney: NSW Bureau of Crime Statistics and Research.

[16] Cheatwood D. Is there a season for homicide? In: Criminology 2008; 26: 287-306

[17] Landau SF, Fridman D. The Seasonality of Violent Crime - The Case of Robbery and Homicide in Israel. In: Journal of Research in Crime and Delinquency 1993; 30: 163-191

[18] Hipp JR, Bauer DJ, Curran PJ, Bollen KA. Crimes of Opportunity orCrimes of Emotion? Testing Two Explanations of Seasonal Change in Crime. In: Social Forces 2004; 82: 1332-1340. 